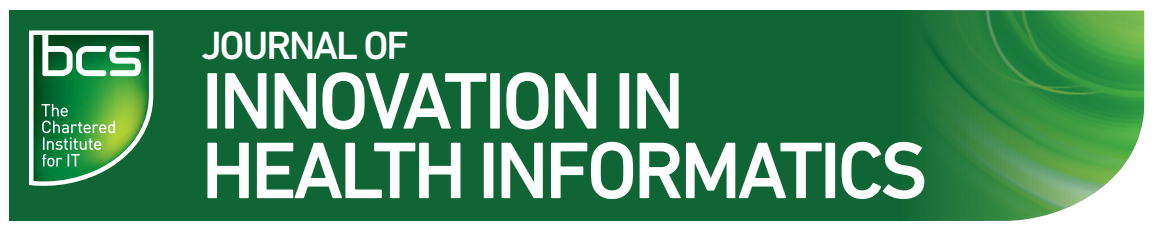

\title{
Editorial
}

Copyright $\odot 2017$ The Author(s). Published by BCS, The Chartered Institute for IT under Creative Commons license http://creativecommons.org/ licenses/by/4.0/

\section{Genesis of a UK Faculty of Clinical Informatics at a time of anticipation for some, and ruby, golden and diamond celebrations for others}

\author{
Simon de Lusignan \\ Professor of Primary Care and Clinical Informatics, Department of Clinical and Experimental Medicine, University \\ of Surrey, Guildford, UK \\ Editor-in-Chief Journal of Innovation in Health informatics \\ Jeremy Barlow \\ Director of Standards, BCS, The Chartered Institute for IT, Swindon, UK \\ Chair, Fed-IP Management Board \\ Philip J. Scott \\ Senior Lecturer \\ Deputy Editor Journal of Innovation in Health informatics, Centre for Healthcare Modelling \& Informatics, \\ University of Portsmouth, UK
}

\section{INTRODUCTION}

The health informatics community has had variable success over the years to establish its identity, in terms of what defines its core theory, technologies and who its practitioners are. This Editorial coincides with the launch of the UK Faculty of Clinical Informatics (FCl), which will help define clinical informatics practitioners. Simultaneously, we have seen the launch of a Federation of Informatics Professionals (Fed-IP) for those outside the clinically regulated disciplines. Coincidentally, the creation of the faculty coincides with the 40th (ruby), 50th (golden) and 60th (diamond) anniversaries.

- The European Federation for Medical Informatics (EFMI) has celebrated its 40th year. EFMI is a federation of national informatics associations across Europe. It still debates its core theory. ${ }^{1,2}$

- The Royal College of General Practitioners Research and Surveillance Centre has celebrated 50 years of using routine data for national flu and respiratory disease surveillance. ${ }^{3}$ However, the informatics achievement of being one of the first units to recognise the value of routine record data has been an epiphenomenon - a feature flagged by Sullivan as a limitation of our discipline. ${ }^{4}$

- We have celebrated 60 years of the British Computer Society (BCS), which has recognised practitioners through its membership and fellowship, and provided a valued forum for learning and developing practice. ${ }^{5,6}$

\section{DEFINING INFORMATICS AS TECHNOLOGY, ROLE OR BY ITS CORE THEORY}

Staggers and Thompson set out how informatics can be defined by its use of technology, the roles within our discipline or as a concept. Whilst several leaders in our field have suggested that a focus on technology leaves an academic void, potentially obscuring any core academic theory, the development and utilisation 


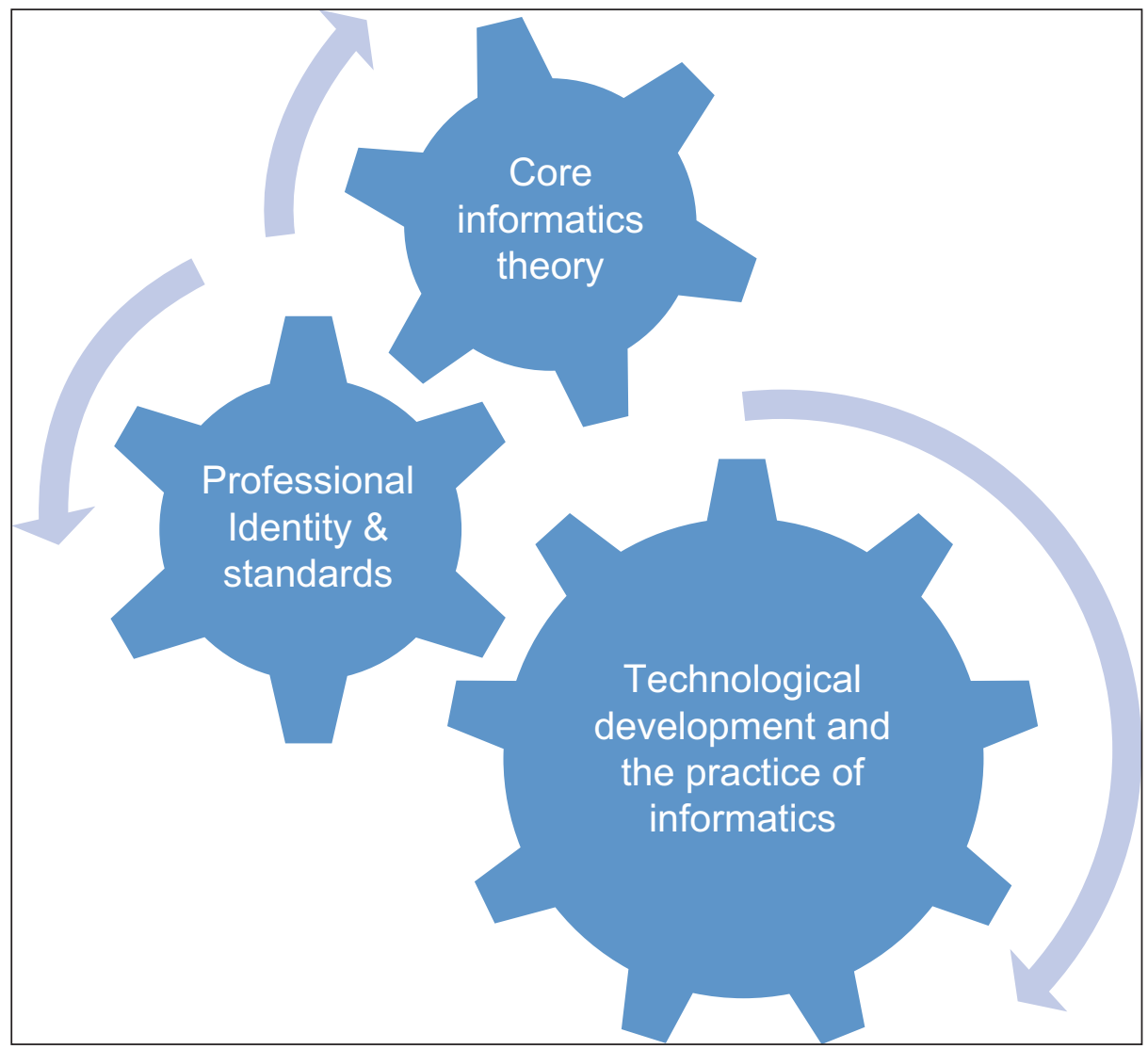

Figure 1 Interplay between theory, roles and technology. The practice and technologies of informatics have been predominant. We anticipate that $\mathrm{FCl}$ and Fed-IP will enhance the professional identity and standards. Informatics core theory requires greater development

of technology remains key to our discipline, and is possibly the largest focus of development (Figure 1). The importance of defining the role of an informatician has long been recognised, and the creation by the International Medical Informatics Association of the International Academy of Health Sciences Informatics, with a cohort of Foundation Fellows, is a marker of the global recognition of the need to better define informatics practitioners. ${ }^{7}$ This is also true of the development of the role of the chief clinical information officer $(\mathrm{CClO})$, albeit the role still lacks a single precise definition. ${ }^{8}$

\section{UK landscape: faculties, federations, colleges and societies}

In the UK, we now have a new $\mathrm{FCl}^{9}$ : a Fed-IP working across health and social care professionals; Royal Colleges that have informatics groups and BCS, the senior learned society in the informatics domain.

\section{UK FCl}

The creation of an $\mathrm{FCl}$ is very welcome. The need for the UK Faculty has not just been driven by a wish to develop informatics as a discipline. Rather, General Medical Council (GMC) requirements for appraisal meant that many clinicians who have taken on informatics roles (e.g. CCIOs and other roles) could no longer appraise in the speciality they originally specialised in, and such roles would be impossible to fill without a route to appraisal and revalidation.

\section{The Fed-IP in health and care}

Fed-IP is the UK-focused, but internationally connected, registration body for health and care informatics professionals. ${ }^{10}$ The professional institutions that are members of Fed-IP collaborate to set and maintain the professional standards of health and care informatics, including the publication of a professional register. It will begin professionally registering individuals in early 2018 . The founder member bodies are:

- Institute of Health Records and Information Management;

- Socitm - The Society for IT practitioners in the public sector;

- CILIP - The Library and Information Association;

- BCS - The Chartered Institute for IT.

Whilst progress is being made, Fed-IP currently lacks the equivalent driver to the GMC, and other clinical professional bodies.

\section{Royal colleges and societies}

The various UK Royal Colleges generally have informatics groups, for example, the Royal College of Physicians Health Informatics Unit. Their focus tends to be on the safe use of technology, record and data quality and health informatics careers - a focus on technology and roles, rather than on developing core theory. BCS, with its Royal Charter, and its membership, fellowships and ability to award chartered status has many similarities to the Royal Colleges associated with the clinical specialisms. However, BCS has 
looked to work collaboratively with other bodies to accredit the heath and care informatics role, in recognition that it is a broad field.

\section{CONCLUSION}

The creation of $\mathrm{FCl}$ and Fed-IP are very welcome. We hope that the two bodies will continue their cooperative relationship and converge as far as regulation will permit. Alongside

\section{REFERENCES}

1. Haux R et al. Research strategies for biomedical and health informatics. Some thought-provoking and critical proposals to encourage scientific debate on the Nature of Good Research in Medical Informatics. Methods of Information in Medicine 2017;56:e1-e10. doi: 10.3414/ME16-01-0125.

2. Scott PJ, Georgiou A, Hyppönen $H$, Craven $C K$, Rigby $M$ and Brender McNair J. Theoretical foundations for evidence-based health informatics: why? how? Studies in Health Technology and Informatics 2016;228:614-8.

3. de Lusignan $S$ et al. RCGP Research and Surveillance Centre: 50 years' surveillance of influenza, infections, and respiratory conditions. British Journal of General Practice 2017;67(663):440-41. doi: 10.3399/bjgp17X692645.

4. Sullivan F. What is health informatics? Journal of Health Services Research \& Policy 2001;6(4):251-4.

5. Runciman B. Celebrating 60 years of BCS: part 1: 1957 to 1986 the first 30 years. ITNow 2017;22-62. Available from: http://www.bcs.org/content/ConWebDoc/57538. Accessed 18 December 2017. the importance of technology, we are seeing recognition of the role of the informatician. Interestingly, we are seeing a new generation of bodies forming internationally, specifically to reinforce professional roles in informatics. The ongoing challenge for our discipline is better definition of its core theory. We see a role for this journal in documenting and critically appraising these developments. It is great to see the genesis of this new faculty - at a time when others are celebrating ruby, golden and diamond jubilees.

6. Runciman B. Celebrating 60 years of BCS: part 2: 1987 to 2016 the second 30 years. ITNow 2017;22-58. Available from: http://www.bcs.org/content/ConWebDoc/57538. Accessed 18 December 2017.

7. Lehmann CU, Park HA, Shortliffe EH and Degoulet P. The International Academy of Health Sciences Informatics: an academy of excellence. Yearbook of Medical Informatics 2017;26(1):7-8. doi: 10.15265/IY-2016-015.

8. Kannry $\mathrm{J}$ et al. The Chief Clinical Informatics Officer (CCIO): AMIA task force report on $\mathrm{CClO}$ knowledge, education, and skillset requirements. Applied Clinical Informatics 2016;7(1):143-76. doi: 10.4338/ACl-2015-12-R-0174.

9. Faculty of Clinical Informatics. Available from: https://www.facultyofclinicalinformatics.org.uk/. Accessed 18 December 2017.

10. The Federation of Informatics Professionals in Health and Care (Fed-IP). Available from: http://fed-ip.org/. Accessed 18 December 2017. 